\title{
Application of Rotary Drum Dryer at Ombilin Coal Fired Power Plant
}

\author{
Mujammil Asdhiyoga Rahmanta and Muhammad Iqbal Felani
}

\begin{abstract}
PLN as State-Owned Company of Indonesia has 10.000 MW fast track projects of Coal Fired Power Plant (CFPP) which is designed for using Medium Rank Coal (MRC). PLN has not got MRC due to government policy of trading of coal. While Indonesia has a lot of Low Rank Coal (LRC) reserves nowadays. Ombilin CFPP 2X100 MW has used rotary drum dryer to increase High Heating Value (HHV) of LRC by reducing total moisture of water in coal. Rotary drum dryer uses flue gas from its furnace as heat source. Rotating test in various speeds is used to know the characteristic product (fixed carbon, total moisture, and HHV) of rotary drum dryer at Ombilin CFPP. The temperature of flue gas (heat source), the type of coal input, and the other operation parameters are maintained approximately constant when speed is adjusted.
\end{abstract}

Index Terms-High heating value, rotary drum dryer, rotating speed, total moisture.

\section{INTRODUCTION}

Proximate analysis of coal is divided coal into 4 parts such as moisture content, volatile matter, fixed carbon, and ash content. Coal deposits which can generate heat energy through combustion reaction are volatile matter and fixed carbon [1]. Removing moisture content of coal by drying can increase HHV. Drying occurs by effecting vaporization of the liquid by supplying heat to the wet feedstock. As noted earlier, heat may be supplied by convection (direct dryers), by conduction (contact or indirect dryers), radiation or volumetrically by placing the wet material in a microwave or radio frequency electromagnetic field. Over 85 percent of industrial dryers are of the convective type with hot air or direct combustion gases as the drying medium. Over 99 percent of the applications involve removal of water. All modes except the dielectric (microwave and radio frequency) supply heat at the boundaries of the drying object so that the heat must diffuse into the solid primarily by conduction. The liquid must travel to the boundary of the material before it is transported away by the carrier gas (or by application of vacuum for non-convective dryers) [2].

An experimental and numerical study has been carried out by researchers on coal drying and rotary dryer designs. Yilmazoglu et al. [3] compared the performance of a rotary dryer by using two kinds of heat source. He used natural gas burner and parabolic solar system as heat sources. Margono et al. [4] analyzed the effects of feed rate and residence time in rotary dryer using steady-state and unsteady-state plug flow models. Partial differential equations describing heat

Manuscript received January 16, 2015; revised March 28, 2015.

The Authors are with PLN Indonesia, Indonesia (e-mail: jammilrahman13@gmail.com, iqbalfelani_tm04@yahoo.com). and mass transfer in the rotary dryer were derived from shell balance. The results show that evaporated feed moisture content in plug flow back mixing model was lower than in plug flow model. Drying system is used in processes to obtain the required moisture content of the feed. Fagernas $e t$ al. [5] compared several types of dryers in a biomass drying process. They also investigated the environmental effects of dryers and offered different dryer types with respect to the feed characteristic and feed mass flow rate. Kakaras et al. [6] performed a simulation to investigate the effects of brown coal drying on a thermal power plant. Different types of dryers were compared and the thermal efficiency of the power plant was improved 5\% by drying.

For each and every product, there is a representative curve that describes the drying characteristics for that product at specific temperature, velocity and pressure conditions. Fig. 1 shows a typical drying curve. The variations in that curve will occur principally in relative rate to carrier velocity and temperature.

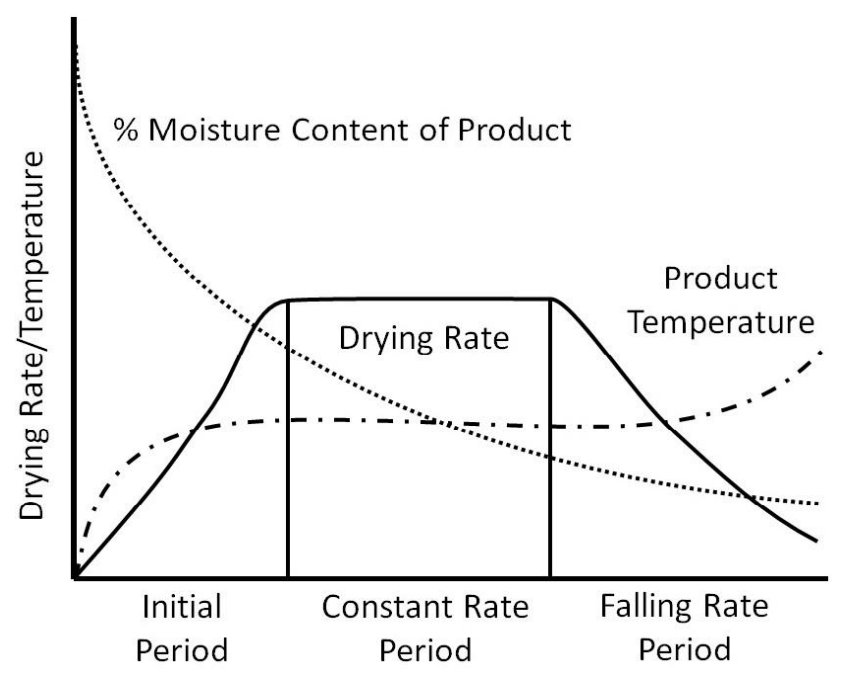

Fig. 1. Drying curve [7].

The first phase (initial period) is where sensible heat is transferred to the product and the contained moisture. This is the heating up of the product from the inlet condition to the process condition, which enables the subsequent processes to take place. The rate of evaporation increases dramatically during this period with mostly free moisture being removed. In some instances, pre-processing can reduce or eliminate this phase. The second phase (constant rate period) is when the free moisture persists on the surfaces and the rate of evaporation alters very little as the moisture content reduces. During this period, drying rates are high and higher inlet air temperatures than in subsequent drying stages can be used without detrimental effect to the product. There is a gradual 
and relatively small increase in the product temperature during this period. The third phase (falling rate period) is the phase during which migration of moisture from the inner interstices of each particle to the outer surface becomes the limiting factor that reduces the drying rate.

There are several types of coal dryer such as rotary drum dryer, mechanical spouted dryer, screw conveyor dryer, and fluidized bed dryer [7]-[9]. Rotary drum dryer can use flue gas or steam as heat source. Rotary dryer rotates coal to make heat distribution inside the drum. Screw conveyor dryer use screw mechanism to move the coal and distribute heat. Steam is used as heat source to dry the coal. Spouted dryer used horizontal screw to rotate the coal and distribute heat. Flue gas generated from furnace is blown from the bottom of container. Heat source has different direction or counter flow with the coal. Fluidized bed dryer uses hot gas that flowed into the bed that contains granules/particles of the object to be dried. With a certain velocity, hot gas will cause the particles mixed and then at a certain moment that have been dried particles will be carried out of the bed.

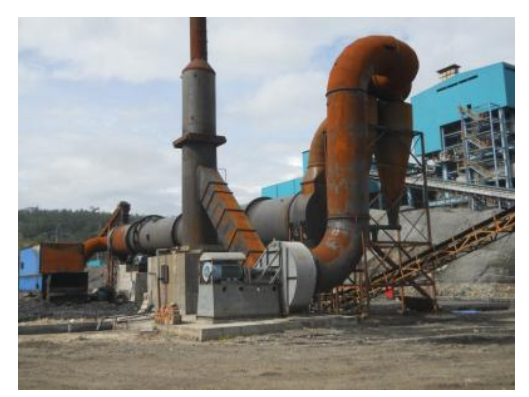

(a) Side view

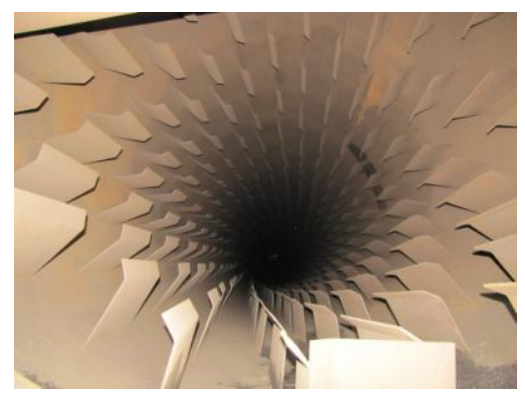

(b) Inner rotary drum

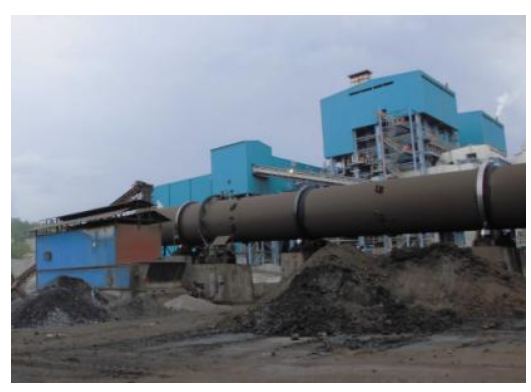

(c) furnace of dryer

Fig. 2. Rotary drum dryer at Ombilin CFPP.

Fig. 2 shows rotary drum dryer at Ombilin CFPP $2 \times 100$ MW. It is located at the plant site. It has capacity $30 \mathrm{ton} / \mathrm{h}$ and heat source from flue gas which produced by coal furnace. It has $30 \mathrm{~m}$ of length and $3 \mathrm{~m}$ of diameter. The size input of coal is $3-4 \mathrm{~cm}$. The flue gas has temperature approximately $300{ }^{\circ} \mathrm{C}$ and direct contact with coal in order for drying. This rotary drum dryer has supplied $20 \%$ of fuel in Ombilin CFPP.

\section{METHODOLOGY AND EXPERIMENT}

\section{A. Methodology}

Experiment is conducted by testing of operational rotary drum dryer in various speed of rotation $(14,15$, and $16 \mathrm{rpm})$. The temperature of flue gas is maintained in range at $300{ }^{\circ} \mathrm{C} \pm$ $30{ }^{0} \mathrm{C}$. Coal which tested is came from same mine. The relationship between rotating speed with decreasing moisture, increasing fixed carbon, and HHV of rotary drum dryer is known by this experiment.

\section{B. Experiment of Operational Rotary Drum Dryer}

The speed is adjusted into 14, 15, and 16 rpm every 1 hour. Speed correlate with the resident time of heating coal, it means that lower speed will make heating time to be longer and higher water content in coal will be evaporated. But, low speed will reduce the capacity. High speed will increase capacity but reducing water content in coal will be lower. The experiment is held at $18^{\text {th }}-19^{\text {th }}$ July 2013 .

\section{RESULT AND ANALYSIS}

\section{A. Coal Properties}

TABLE I: PROXIMATE ANALYSIS OF COAL

\begin{tabular}{|c|c|c|c|c|c|}
\hline \multirow[b]{2}{*}{$\begin{array}{c}\text { Rotating } \\
\text { speed } \\
(\mathrm{rpm})\end{array}$} & \multirow[b]{2}{*}{ Coal } & \multicolumn{4}{|c|}{ Proximate Analysis } \\
\hline & & $\begin{array}{c}\text { Total } \\
\text { moisture } \\
(\%)\end{array}$ & $\begin{array}{l}\text { Ash } \\
(\%)\end{array}$ & $\begin{array}{c}\text { Volatile } \\
\text { matter } \\
(\%)\end{array}$ & $\begin{array}{c}\text { Fixed } \\
\text { carbon } \\
(\%)\end{array}$ \\
\hline \multirow{2}{*}{14} & Input & 33.08 & 5.95 & 35.92 & 25.05 \\
\hline & Output & 23.08 & 6.24 & 40.01 & 30.67 \\
\hline \multirow{2}{*}{15} & Input & 35.81 & 4.93 & 33.88 & 25.38 \\
\hline & Output & 27.22 & 4.9 & 38.19 & 29.68 \\
\hline \multirow{2}{*}{16} & Input & 32.67 & 5.85 & 35.93 & 25.55 \\
\hline & Output & 25.13 & 5.64 & 39.50 & 29.73 \\
\hline
\end{tabular}

Table I shows that reducing water content or total moisture by drying will increase fixed carbon content. Volatile matter will increase but ash content remains constant after drying.

TABLE II: PROPERTY DIFFERENCE AND CALORIC VALUE OF COAL

\begin{tabular}{|c|c|c|c|c|c|}
\hline \multirow[b]{2}{*}{$\begin{array}{c}\text { Rotating } \\
\text { speed } \\
(\mathrm{rpm})\end{array}$} & \multirow[b]{2}{*}{ Coal } & \multicolumn{2}{|c|}{ Proximate Analysis } & \multirow[b]{2}{*}{$\begin{array}{c}\text { HHV } \\
(\mathrm{kCal} / \mathrm{kg})\end{array}$} & \multirow[b]{2}{*}{$\begin{array}{c}\text { Increasing } \\
\text { HHV } \\
(\%)\end{array}$} \\
\hline & & $\begin{array}{c}\text { Reducing } \\
\text { total } \\
\text { moisture } \\
(\%)\end{array}$ & $\begin{array}{c}\text { Increasing } \\
\text { fixed } \\
\text { carbon } \\
(\%)\end{array}$ & & \\
\hline \multirow[t]{2}{*}{14} & Input & \multirow[t]{2}{*}{30.23} & \multirow[t]{2}{*}{22.44} & $4,022.32$ & \multirow[t]{2}{*}{16.81} \\
\hline & Output & & & $4,698.52$ & \\
\hline \multirow[t]{2}{*}{15} & Input & \multirow[t]{2}{*}{23.99} & \multirow[t]{2}{*}{16.94} & $4,005.84$ & \multirow[t]{2}{*}{12.54} \\
\hline & Output & & & $4,508.32$ & \\
\hline \multirow[t]{2}{*}{16} & Input & \multirow[t]{2}{*}{23.08} & \multirow[t]{2}{*}{16.36} & $4,146.97$ & \multirow[t]{2}{*}{10.80} \\
\hline & Output & & & $4,594.76$ & \\
\hline
\end{tabular}

Table II shows the percentages of reducing of total moisture, increasing fixed carbon and $\mathrm{HHV}$ of coal 
properties.

\section{B. Total Moisture}

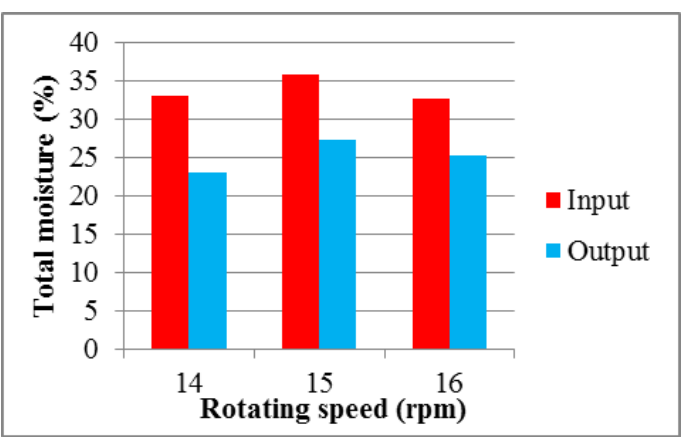

(a) Rotating speed vs total moisture

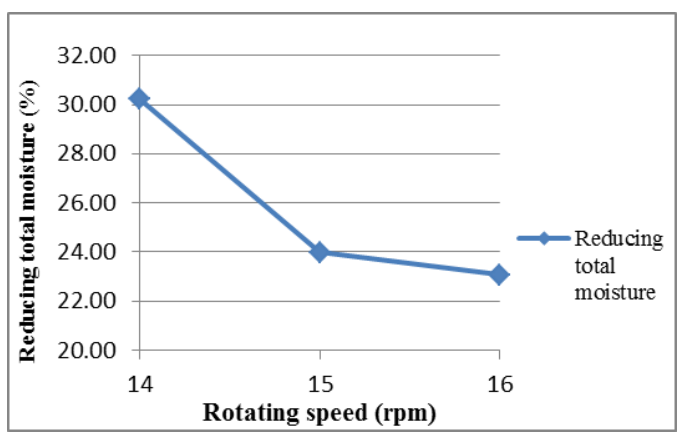

(b) Rotating speed vs reducing total moisture

Fig. 3. Graph between rotating speed and total moisture.

The Fig. 3 shows that rotating speed at $14 \mathrm{rpm}$ reduces $30.23 \%$ of total moisture from $33.08 \%$ into $23.08 \%, 15 \mathrm{rpm}$ reduces $23.99 \%$ of total moisture from $35.81 \%$ into $27.22 \%$, and $16 \mathrm{rpm}$ reduces $23.08 \%$ of total moisture from $32.67 \%$ into $25.31 \%$. Lower rotating speed has made higher water content to be evaporated and reducing higher total moisture in coal.

\section{Fixed Carbon}

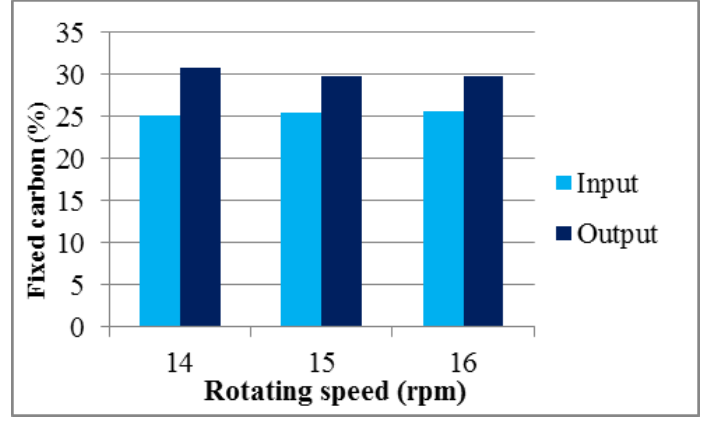

(a) Rotating speed vs fixed carbon

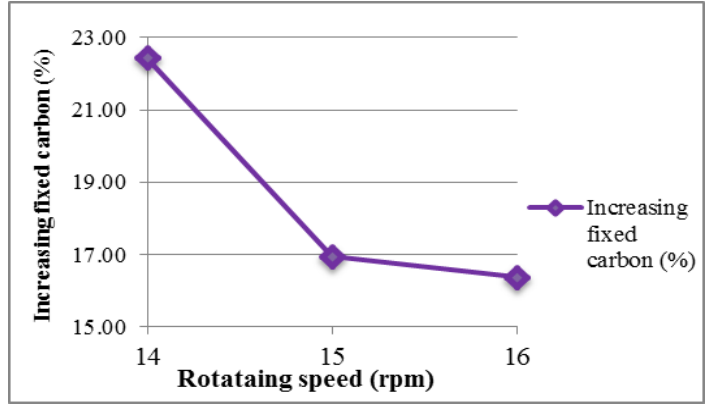

(b) Rotating speed vs increasing fixed carbon

Fig. 4. Graph between rotating speed and fixed carbon.
Fig. 4 indicates that rotating speed at $14 \mathrm{rpm}$ increases $22.44 \%$ of fixed carbon from $25.05 \%$ into $30.67 \%, 15 \mathrm{rpm}$ increases $16.94 \%$ of fixed carbon from $25.38 \%$ into $29.68 \%$, and $16 \mathrm{rpm}$ increases $16.36 \%$ of fixed carbon from $25.55 \%$ into $29.73 \%$. Lower rotating speed has made higher of increasing fixed carbon. Fig. 4 (b) and Fig. 5 (b) have similar trend, they show that higher reducing of total moisture will have made higher increasing of fixed carbon and lower reducing of total moisture will have made lower increasing of fixed carbon.

\section{High Heating Value}

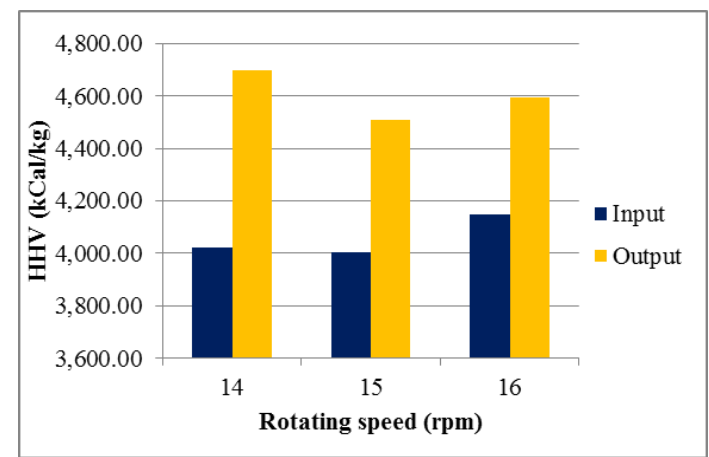

(a) Rotating speed vs HHV

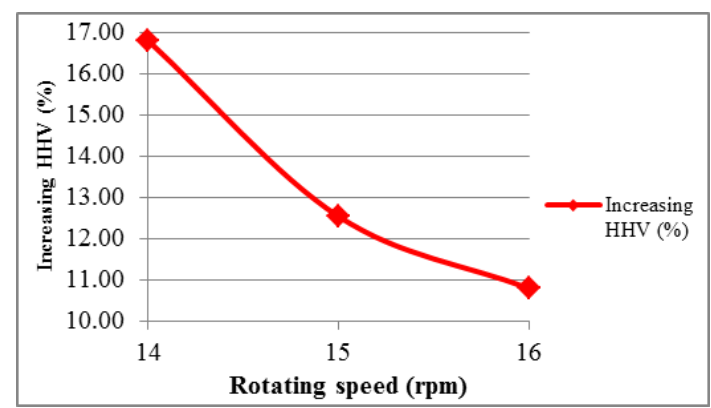

(b) Rotating speed vs increasing of HHV

Fig. 5. Graph between rotating speed and high heating value.

Fig. 5 shows that rotating speed at $14 \mathrm{rpm}$ increases HHV about $16.81 \%$ from $4,022 \mathrm{kCal} / \mathrm{kg}$ into $4,698 \mathrm{kCal} / \mathrm{kg}, 15$ $\mathrm{rpm}$ increases HHV about $12.54 \%$ from $4,005 \mathrm{kCal} / \mathrm{kg}$ into $4,508 \mathrm{kCal} / \mathrm{g}$, and $16 \mathrm{rpm}$ increases HHV about $10.80 \%$ from $4,146 \mathrm{kCal} / \mathrm{kg}$ into $4,594 \mathrm{kCal} / \mathrm{kg}$. Lower rotating speed has made higher of increasing HHV of coal.

\section{CONCLUSION}

Rotary drum dryer at Ombilin CFPP has characteristic which depended on the rotating speed of dryer. Rotating speed at $14 \mathrm{rpm}$ reduces $30.23 \%$ of total moisture and increases $22.44 \%$ of fixed carbon. Rotating speed at $15 \mathrm{rpm}$ reduces $23.99 \%$ of total moisture and increases $16.94 \%$ of fixed carbon. Rotating speed at $16 \mathrm{rpm}$ reduces $23.08 \%$ of total moisture and increases $16.36 \%$ of fixed carbon.

Highest increasing of HHV about $16.81 \%$ has been happened when rotating speed is $14 \mathrm{rpm}$. Lowest increasing of $\mathrm{HHV}$ about $10.80 \%$ has been happened when rotating speed is $16 \mathrm{rpm}$.

Adjusting lower rotating speed of rotary drum dryer makes higher reducing of total moisture, it will have made higher 
increasing of fixed carbon and HHV. Adjusting higher speed of rotary drum dryer makes lower reducing of total moisture, it will have made lower increasing of fixed carbon and HHV.

\section{ACKNOWLEDGMENT}

This work is financially supported by Research Institute of PLN Indonesia.

\section{REFERENCES}

[1] L. D. Smoot and P. J. Smith, Coal Combustion and Gasification, Plenum Press, New York, 1985.

[2] A. S. Mujumdar, Industrial Handbook of Drying, $3^{\text {rd }}$ ed., CRC/Taylor\&Francis, 2007.

[3] M. Z. Yilmazoglu and E. Amirabedin, "3E analysis of a solar assisted rotary type coal dryer," Renewable Energy Research, vol. 2, no. 1, 2011.

[4] M. T. H. Morgono, A. Alyway, and S. Kuswandi, "Effects of feed rate and residence time on environment of rotary dryer processes," Applied Sciences in Environmental Sanitation, vol. 4, pp. 11-20, 2009.

[5] L. Fagernas, J. Brammer, C. Wilen, M. Laurer, and F. Verhoeff, "Drying of biomass for second generation synfuel production," Biomass and Bioenergy, vol. 34, pp. 1267-1277, 2010

[6] E. Kakaras, P. Ahladas, and S. Syrmopoulos, "Computer simulation studies for the integration of an external rryer into a greek-lignite fired power plant," Fuel, vol. 81, pp. 583-593, 2002.
[7] Best Practice Manual Dryers, Devki Energy Consultancy Pvt. Ltd. 2006, p. 5.

[8] A. S. Mujamdar, Industrial Transfer Process, Department of Mechanical Engineering National University of Singapore, 2012.

[9] T. Kudra and A. S. Mujumdar, Advanced Drying Technologies, $2^{\text {nd }}$ ed., CRC Press, 2009.

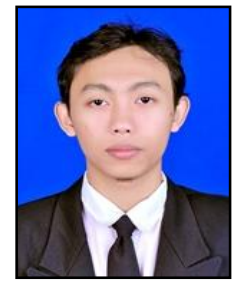

Mujammil Asdhiyoga Rahmanta was born on July 15, 1988 in Gunung Kidul, Special Province of Yogyakarta, Indonesia. He received his B.Eng. degree in mechanical engineering from Gadjah Mada University in 2011. Now he is a research staff member of research institute of PLN Indonesia. He conducts the research in primary energy and coal utilisation such as coal walter slurry, dryer and gasification,

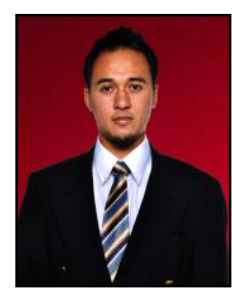

Muhammad Iqbal Felani was born on April 16,1986 in Temanggung, Central Java, Indonesia. He received his B.Eng degree in mechanical engineering from Universitas Gadjah Mada in 2008. He also received M.Eng. degree in electrical engineering from Institute of Technology Bandung in 2011. Now he is an researcher in Research Institute of PLN Indonesia. He conduct the research in reliability, risk management and optimization. 